\title{
Theoretical modelling and experimental investigation of a thermal energy storage refrigerator
}

\author{
A. C. Marques ${ }^{\text {a,b,** }}$, G.F. Davies ${ }^{\text {a }}$, J. A. Evans ${ }^{\text {a }}$, G.G. Maidment ${ }^{\text {a }}$, I. D. Wood ${ }^{\text {b }}$ \\ (a) Department of Urban Engineering, London South Bank University, 103 Borough Road, London, SE1 0AA, UK; \\ (b) Adande Refrigeration, 45 Pinbush Road, South Lowestoft Industrial Estate, Lowestoft, Suffolk, NR33 7NL, UK
}

\begin{abstract}
Numerical simulations using the computational fluid dynamics (CFD) software ANSYS Fluent were undertaken to characterize the airflow and temperature distribution in a natural convection thermal energy storage household refrigerator. The model compared the refrigerator temperature stability with different phase change materials (PCM) incorporated into the storage compartment. Scenarios investigated included the PCM orientation (vertical or horizontal), PCM temperature (use of water or eutectics) and compartment designs (conventional or drawer type appliance). The results suggested that a horizontal PCM configuration produces lower compartment temperatures than a vertical configuration. The temperature distribution with a horizontal PCM was tested experimentally and the results were in agreement with the CFD predictions. Both the simulation and the experimental results suggest that a eutectic with a phase change temperature below $0^{\circ} \mathrm{C}$ must be employed to maintain the compartment temperature within acceptable limits. The model indicated that combining horizontal and vertical PCMs in a full height compartment or dividing the same compartment into two drawers with a horizontal PCM configuration for each drawer are feasible design options for the household thermal storage refrigerator.
\end{abstract}

Keywords: Household refrigerator, phase change material, energy storage, temperature distribution, CFD

\section{Introduction}

Domestic refrigerators are among the most energy demanding appliances in a household due to their near continuous operation. In the UK, cold appliances are responsible for $17 \%$ of average household electricity use [1]. Worldwide it has been estimated that there is one household refrigerator for every six people on Earth, which corresponds to approximately $6 \%$ of the total electrical energy produced [2]. In order to reduce greenhouse gas emissions from these appliances, governments have adopted mandatory energy standards and energy labelling programs to regulate the household refrigeration market by setting appliance performance targets.

The most common approaches to reduce the energy consumption of household refrigerators to date include the use of optimised insulation, energy efficient compressors and enhanced heat transfer in heat exchangers. Vacuum insulated panels (VIPs) offer twice the level of insulation of polyurethane foam; nevertheless their reliability over lifespan and high manufacturing and disposal costs has prevented their widespread use [3]. The compressor is the single largest energy user in a refrigerator, responsible for more than $80 \%$ of the total energy consumed by the appliance [4]. Compressor manufacturers have developed variable speed compressors that adjust the refrigeration capacity in relation to the load by controlling the motor speed resulting in energy savings of up to $40 \%$ [5]. However this technology is still very expensive limiting its use in a market that is particularly sensitive to price.

The use of phase change materials (PCMs) to accumulate thermal energy in household refrigerators is a new approach to improving the energy efficiency of these appliances. PCMs have high latent heat content and freeze and melt at a specific (nearly constant) temperature, accumulating or releasing large quantities of energy during the process. In the household refrigerator, the cooling capacity stored in the PCM can be used to stabilize the temperature in the compartment, for example, by reducing the effects of peak loads and cooling losses during periods when the door is open. Azzouz et al. [6] have tested a household refrigerator with a PCM slab in thermal contact with a vertical evaporator allowing the refrigerator to maintain a compartment temperature of $5^{\circ} \mathrm{C}$ without power supply for 5 to 9 hours depending on the thermal load.

Abbreviations: CFD, computational fluid dynamics; DDC, dynamic demand control; PCM, phase change material; PIV, particle image velocimetry; PRESTO, pressure staggering option; SIMPLE, semi-implicit method for pressure linked equations; VIPs, vacuum insulated panels

* Corresponding author: Tel.: +44 1502576716; Fax: +44 1502533794

E-mail address: marquesc@1sbu.ac.uk 


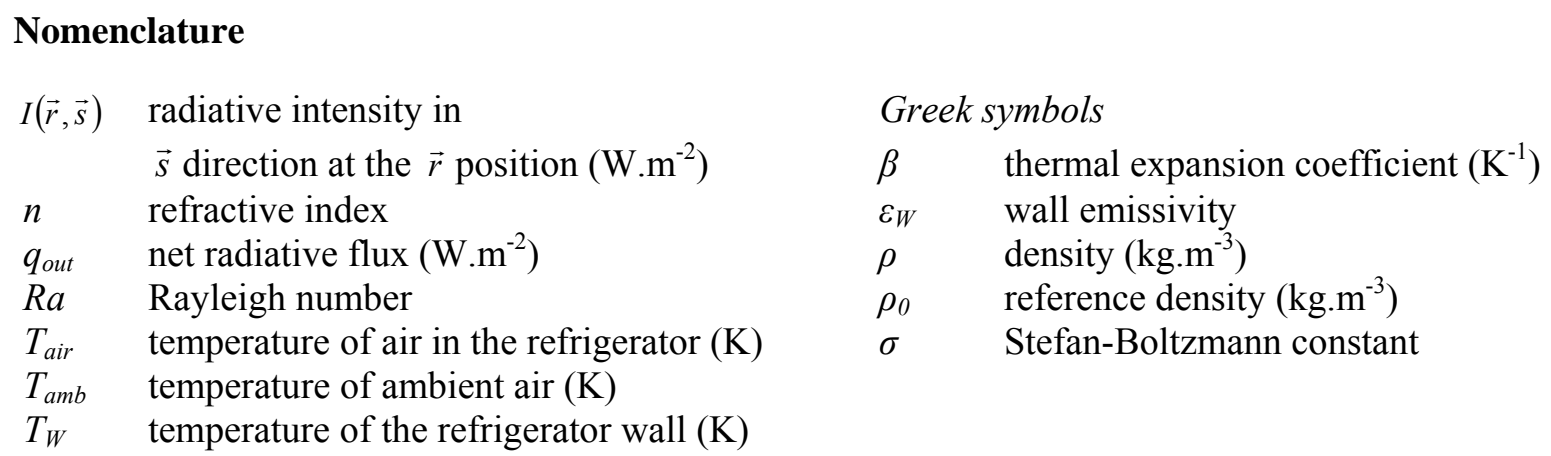

$T_{W} \quad$ temperature of the refrigerator wall (K)

\section{Greek symbols}

$\beta \quad$ thermal expansion coefficient $\left(\mathrm{K}^{-1}\right)$

$\varepsilon_{W} \quad$ wall emissivity

$\rho \quad$ density $\left(\mathrm{kg} \cdot \mathrm{m}^{-3}\right)$

$\rho_{0} \quad$ reference density $\left(\mathrm{kg} . \mathrm{m}^{-3}\right)$

$\sigma \quad$ Stefan-Boltzmann constant

Another experimental study carried out by Cheng et al. [7] analysed the performance of a fridge-freezer with a PCM fitted around the condenser pipes, which lowered the condensing temperature and produced energy savings of $12 \%$ compared to the same fridge-freezer without thermal storage. Gin et al. [8] covered $26 \%$ of the internal walls of a frost free upright freezer with PCM panels reducing peak air and product temperature by $3^{\circ} \mathrm{C}$ and $1^{\circ} \mathrm{C}$ respectively during an electric defrost.

Numerous studies have shown that conventional household refrigerators run at a higher temperature than recommended by health and food safety legislation during real usage operation. In fact an analysis of various surveys reported in the last 30 years has shown that $61.2 \%$ of refrigerators throughout the world run at temperatures above $5^{\circ} \mathrm{C}[9,10]$. There are currently two types of household refrigerators in the market: static and frost free; these distinctions indicate differences in the airflow and heat transfer mechanism within the refrigerated compartment. Frost-free refrigerators have a fan that forces the warm air from the compartment onto the evaporator where it is then cooled and dehumidified before returning to the refrigerated compartment. In static refrigerators heat is transferred by natural convection, which produces a buoyant airflow. The evaporator position within the compartment (horizontal/vertical) determinates the distribution of warm and cold zones. Amara et al. [11] carried out experimental measurements using particle image velocimetry (PIV) to characterize airflow due to natural convection in a static refrigerator. The evaporator was positioned vertically and a circular flow was produced in the compartment resulting in a stratified temperature distribution with warmer air at the top and cold air at the bottom. However, positioning the evaporator horizontally produces unsteady flow as heavier cold air is generated above lighter warm air. The colder air sinks through the warm air resulting in more mixing and a less stratified temperature profile [12, 13]. The temperature stability is generally better in forced convection refrigerators than in static natural convection models, however, their energy consumption is considerably higher.

This paper describes a computational fluid dynamics (CFD) simulation of the airflow and temperature distribution in a natural convection refrigerator incorporating PCMs to increase its thermal energy storage capacity. The aim was to evaluate the most effective configuration for the PCM/evaporator assembly (i.e. vertical or horizontal) by studying its effect on the airflow patterns and temperature distribution within the refrigerator cavity. The vertical PCM model was validated against published literature and the horizontal PCM simulation has been validated experimentally using an experimental rig specifically developed for that purpose. Additional design options were investigated through simulation; these include a combined horizontal and vertical PCM configuration, different PCM temperatures and different compartment designs (door and/or drawer appliance). Using the results from the analysis, the best options for maximising energy efficiency while maintaining a uniform temperature distribution were identified.

Thermal storage refrigerators can potentially be integrated with dynamic demand control (DDC) to further improve efficiency. DDC is a technology that adjusts the load demands on an electrical power grid. Appliances under DDC operation can reduce peak demand on the National Grid and therefore help balance demand and supply. DDC can be incorporated in the appliance control system, e.g. thermostatic control in a refrigerator. The device monitors the frequency of the power grid and turns the appliance on or off for a few seconds, according to the local power demand. DDC operation has been tested in household refrigerators and freezers, and it was found that their temperature was increased by 1 and $1.5^{\circ} \mathrm{C}$ respectively and the predicted carbon emissions savings were estimated to be 2 million tonnes per year [14]. Thermal storage refrigerators integrated with DDC provide the ideal solution, since the appliance has long off-time periods, i.e. several hours, and its temperature remains constant during the PCM discharge, thereby enabling better temperature control than simply employing DDC on a conventional refrigerator. 


\section{CFD simulations}

The commercial CFD software ANSYS 13.0 was employed to carry out the 3D simulations; the code uses the finite volume based Fluent solver.

\subsection{Assumptions and boundary conditions}

Only half of the refrigerator compartment (dimensions: $0.75 \times 0.45 \times 0.23 \mathrm{~m}$ ) was modelled due to the symmetry of its parallelepiped geometry. A hexahedral mesh consisting of 455,400 cells was used. The size of the cells was reduced and the number of cells increased nearer to the walls to enable the thermal layer to be simulated more effectively. A sensitivity study on the mesh was carried out to ensure that the simulation results were not influenced by the number of cells. In order to simplify the model, the melting/freezing process for the PCM was not included in the model; instead the effect of the PCM was simulated as a boundary condition of constant temperature $\left(0^{\circ} \mathrm{C}\right)$ either at the top or back wall of the refrigerator. The thin wall approach was used for the other compartment walls, which were assumed to be subjected to a constant external temperature of $25^{\circ} \mathrm{C}$. The thin wall approach simulates the effect of the thermal resistance of the wall in the normal direction using the material thermal conductivity and thickness. In each case the wall insulation was assumed to be polyurethane with a thermal conductivity of $0.026 \mathrm{~W} \cdot \mathrm{m}^{-1} \cdot \mathrm{K}^{-1}$, and a thickness of $0.05 \mathrm{~m}$.

\subsection{Natural convection and radiation models}

The Rayleigh number (Ra) was calculated for both PCM orientations (horizontal/vertical), based on the characteristic length of the PCM and the temperature difference between the PCM surface and the average internal air (assumed to be $5^{\circ} \mathrm{C}$ ). The calculated Ra was $1 \times 10^{6}$ for the horizontal PCM and $7 \times 10^{7}$ for the vertical PCM, therefore a laminar flow model was assumed for both cases since $\mathrm{Ra}<10^{9}$.

All of the physical properties of the air were assumed to be constant except for the air density for which the Boussinesq approximation was used, as shown in equation 1.

$$
\rho=\rho_{0}\left[1-\beta\left(T_{\text {amb }}-T_{\text {air }}\right)\right]
$$

The Boussinesq approach assumes that the air density is uniform except for the buoyancy term in the momentum equation. This approximation is valid when the variations in air temperature are small, which is expected to be the case here.

Laguerre and Flick [15] have shown that the radiation heat transfer coefficient in refrigerators is of the same order of magnitude as the natural convection heat transfer coefficient; hence radiation cannot be ignored in the household refrigerator. The radiation between the refrigerator surfaces was taken into account using the discrete ordinates radiation model $[11,16]$. For transparent media such as air with negligible absorption and diffusion, the radiation transfer equation in the $\vec{s}$ direction is obtained from equation 2 .

$$
\nabla \cdot(I(\vec{r}, \vec{s}) \vec{s})=0
$$

Where $I(\vec{r}, \vec{s})$ is the radiative intensity in the $\vec{s}$ direction at the $\vec{r}$ position. The refrigerator walls were modelled as gray diffuse and the net radiative flux leaving the surface is given by equation 3 .

$$
q_{\text {out }}=\left(1-\varepsilon_{w}\right)+n^{2} \varepsilon_{w} \sigma T_{w}^{4}
$$

Where, $n$ is the refractive index of the medium next to the wall, $\varepsilon_{\mathrm{w}}$ is the wall emissivity (a value of 0.9 was assumed), $\sigma$ is the Stefan-Boltzmann constant and $T_{w}$ is the wall temperature. An angular discretization analysis was carried out to ensure the results were not affected by the solid angle subdivisions.

The equations were solved for steady state conditions using a pressure based sequential solver. The solver employed the SIMPLE pressure-velocity coupling method and pressure was discretized using the PRESTO scheme. The equations for momentum, energy and radiation were solved using second order upwind discretization for half the calculation period after which a blending factor (first to second order discretization) was enabled. The momentum explicit under-relaxation factor was 0.4 at the beginning of the calculation ( 0.7 is the default), which was then reduced to 0.2 after 500 iterations. For natural convection nonlinear problems, it is recommended to reduce the momentum under-relaxation factor to improve solution convergence [17]. Solution convergence was considered to be reached when the velocity residuals (conservation of momentum) and continuity residuals (conservation of mass) dropped to $10^{-3}$ and energy and the discrete ordinates radiation (conservation of energy) residuals decreased to $10^{-6}$ [17]. 


\section{Experimental setup and methods}

\subsection{Experimental rig}

The experimental rig designed to validate the CFD model was based on a conventional size household undercounter refrigerator, which was cooled by an external coolant system as illustrated in Fig. 1. The coolant system was used instead of a traditional vapour compression system in order to prevent temperature cycling and maintain steady state conditions throughout the experiments.

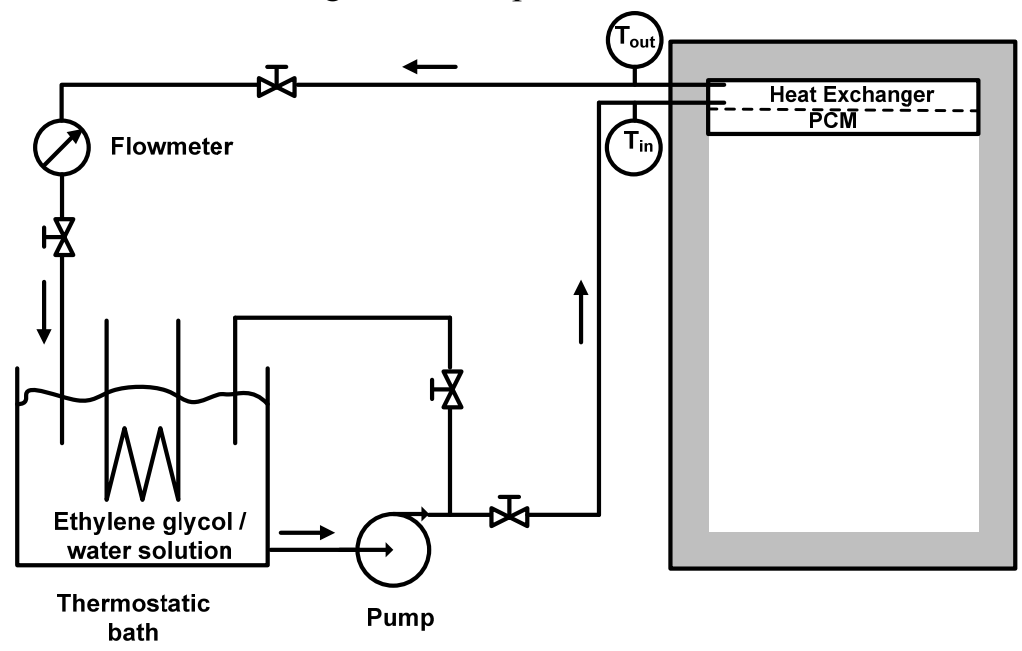

Fig. 1: Schematic of the experimental test rig

The ethylene glycol/water solution was cooled in the thermostatic controlled bath and pumped through the horizontal heat exchanger, freezing the PCM beneath, which then cooled the refrigerator compartment. After exiting the heat exchanger the coolant returned to the thermostatic bath completing the circuit. The inlet ball valve to the heat exchanger was opened at the beginning of each PCM charge cycle and was closed once the PCM temperature readings indicated that the PCM was frozen. The ball valve was located in the inlet line after the pump and allowed for manual regulation of the flow into the heat exchanger. The heat exchanger consisted of $0.002 \mathrm{~m}$ thick copper plate with a copper tube $(0.0064 \mathrm{~m}$ diameter $)$ soldered to the plate surface. The tube was arranged in a spiral shape to ensure that the heat transfer to the PCM was spatially uniform. The PCM employed was pure water (distilled), selected due to: (i) having a suitable phase change temperature; (ii) safety; and (iii) a large latent heat of fusion. The under-counter refrigerator prototype (internal dimensions $0.75 \times 0.45 \times 0.46 \mathrm{~m}$ ) incorporated $0.05 \mathrm{~m}$ thick walls of polyisocyanurate rigid foam, which has an identical thermal conductivity to polyurethane foam. The interior walls of the refrigerator cavity were lined with an acrylonitrile butadiene styrene plastic so that the surface radiation heat transfer coefficient inside the refrigerator prototype would be similar to that for a conventional refrigerator.

\subsection{Temperature measurement}

The temperatures within the PCM and the refrigerator compartment and the ambient temperature were measured with calibrated T-type thermocouples connected to two IOTech Personal Daq/56 data acquisition systems. The thermocouples were calibrated in a temperature controlled Julabo refrigerated/heating circulator bath against a platinum resistance thermocouple with an accuracy of $\pm 0.06 \mathrm{~K}$; the average uncertainty of the temperature measurements was $0.3^{\circ} \mathrm{C}$. A total of 14 thermocouples were distributed uniformly (in 2D) inside the PCM. The air temperature inside the empty refrigerator compartment was measured with 37 hair-thin thermocouples $\left(8 \times 10^{-5} \mathrm{~m}\right.$ diameter $)$ to minimize the impact on the compartment airflow. The thermocouples were distributed in five horizontal layers and three vertical layers in half the refrigerator compartment. Three ambient air temperatures were used for the test room with temperatures controlled to $20^{\circ} \mathrm{C}, 25^{\circ} \mathrm{C}$ and $30^{\circ} \mathrm{C} \pm 0.5^{\circ} \mathrm{C}$ using an air-conditioning system during the experiments.

\section{Results and discussion}

\subsection{Experimental validation}

The first method used to evaluate the accuracy of the current CFD simulations was to model and to compare the results with those for a well-documented case reported previously. Amara et al. [11, 18] simulated the temperature distribution in a household refrigerator prototype with a vertical evaporator and measured the velocity profile in the refrigerated compartment using particle image velocimetry (PIV). In the current 
modelling work, a simulation was carried out for that same refrigerator model as a benchmark and good agreement was found between the benchmark simulation and the previously published experimental results. Simulation of the thermal storage refrigerator with a vertical PCM followed a similar procedure to the benchmark simulation. A converged solution with a comparable airflow and temperature profile were obtained, providing good validatory evidence for the approach used.

The horizontal PCM configuration was validated against experimental data collected from the test rig, as described in section 3. The temperatures measured by the thermocouples were compared with the CFD predictions at exactly the same locations. In order to achieve this, "points" with the same coordinates as the refrigerator thermocouples were created in the domain of the simulated refrigerator to display the CFD temperature predictions in the same locations as the experimentally measured temperatures. The "point" temperatures from the CFD simulation were imported into Excel and plotted against the average experimental temperature measured at the same location. Figs. 2 and 3 illustrate the compartment temperature in the vertical symmetry plane at $\mathrm{z}=0.23 \mathrm{~m}$, for: the CFD prediction (Fig. 2) and for the experimentally measured data (Fig. 3), at an ambient temperature of $25^{\circ} \mathrm{C}$.

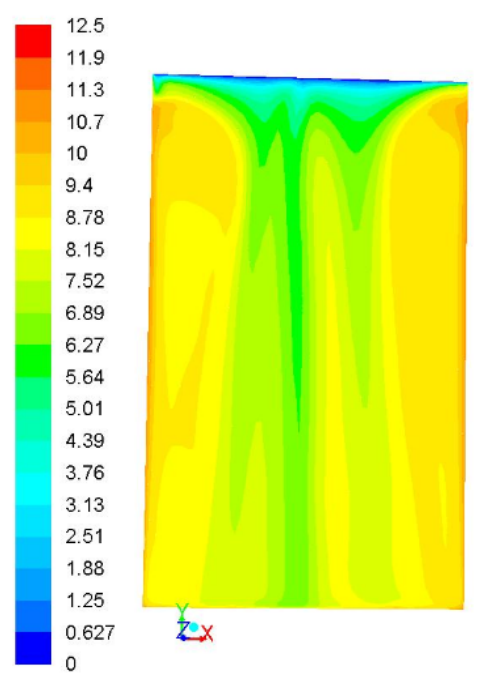

Fig. 2: $\mathrm{CFD}$ predicted temperatures $\left({ }^{\circ} \mathrm{C}\right)$ in the vertical symmetry plane at $\mathrm{z}=0.23 \mathrm{~m}$

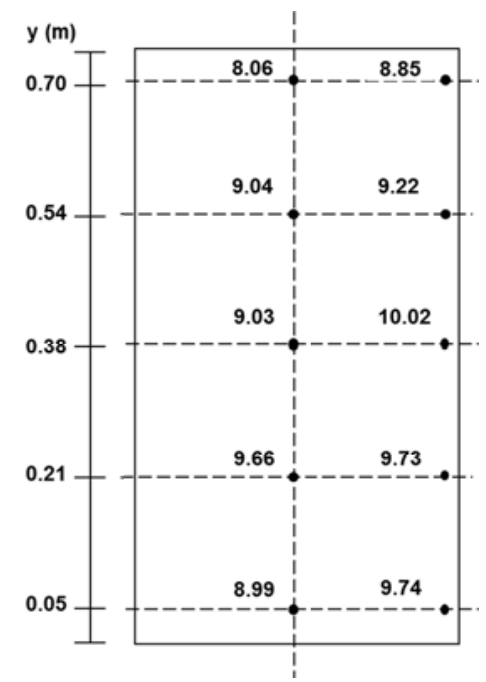

Fig. 3: Experimental temperatures $\left({ }^{\circ} \mathrm{C}\right)$ in the vertical symmetry plane at $\mathrm{z}=0.23 \mathrm{~m}$

The predicted centre temperatures shown for the vertical symmetry plane were marginally lower (by approximately $1.6^{\circ} \mathrm{C}$ ) than the measured temperatures recorded for the refrigerator prototype at the same position. However, the temperatures measured close to the cabinet walls were in close agreement with the CFD prediction (difference $<0.2^{\circ} \mathrm{C}$ ). The compartment temperature in the horizontal symmetry plane at $\mathrm{y}=$ $0.38 \mathrm{~m}$ for both the CFD prediction and the experimentally measured data are presented in Figs. 4 and 5 respectively.

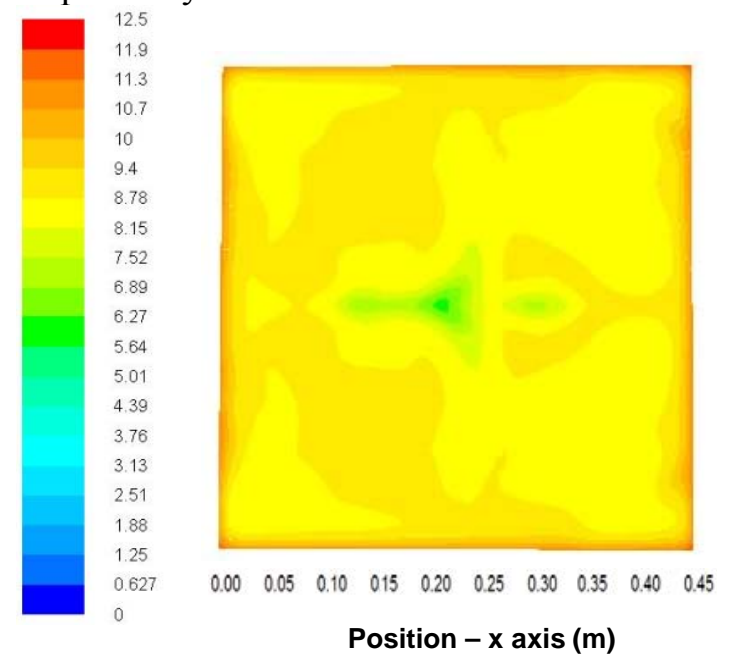

Fig. 4: CFD predicted temperatures $\left({ }^{\circ} \mathrm{C}\right)$ in the horizontal symmetry plane at $\mathrm{y}=0.38 \mathrm{~m}$

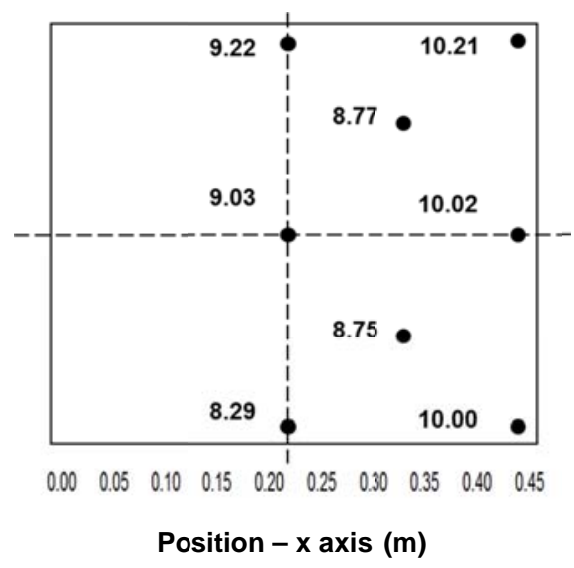

Fig.5: Experimental temperatures $\left({ }^{\circ} \mathrm{C}\right)$ in the horizontal symmetry plane at $\mathrm{y}=0.38 \mathrm{~m}$ 
From Figs. 4 and 5, it is seen that the results predicted and measured for the $\mathrm{y}=0.38 \mathrm{~m}$ horizontal plane showed close agreement (difference $<0.4^{\circ} \mathrm{C}$ ).

Table 1 presents the average and maximum air temperatures predicted by the CFD and measured in the refrigerator compartment at steady state for a range of ambient conditions.

Table 1: Predicted vs. measured air temperatures in the thermal storage refrigerator

\begin{tabular}{ccccccc}
\hline $\begin{array}{c}\text { Ambient } \\
\text { Temperature }\end{array}$ & \multicolumn{2}{c}{$\mathbf{2 0}^{\circ} \mathbf{C}$} & \multicolumn{2}{c}{$\mathbf{2 5}^{\circ} \mathbf{C}$} & \multicolumn{2}{c}{$\mathbf{3 0}^{\circ} \mathbf{C}$} \\
\hline & Measured & Predicted & Measured & Predicted & Measured & Predicted \\
\cline { 2 - 6 } Average & 8.05 & 7.45 & 9.95 & 8.70 & 11.69 & 10.40 \\
Maximum & 10.09 & 10.31 & 12.97 & 12.50 & 15.41 & 14.65 \\
\hline
\end{tabular}

The average predicted compartment temperature was $1{ }^{\circ} \mathrm{C}$ lower than the average compartment temperature measured for the refrigerator prototype. Overall, the predicted CFD temperatures showed close agreement with the experimental temperatures measured in the refrigerated compartment at all ambient temperatures. The error in the average predicted compartment temperature was $7.5 \%$ at $20^{\circ} \mathrm{C}$. For ambient temperatures of $25^{\circ} \mathrm{C}$ and $30^{\circ} \mathrm{C}$, there were slightly higher differences between the average predicted and measured compartment temperatures of $12 \%$ and $11 \%$ respectively. This could be due to a radiation effect on the centre thermocouples leading to higher temperatures being measured and/or their exact location could be a few millimetres away from the compartment centre. The maximum temperatures measured in the compartment, however, were very close to those predicted by the CFD simulation for all ambient temperatures i.e. $20^{\circ} \mathrm{C}, 25^{\circ} \mathrm{C}$ and $30^{\circ} \mathrm{C}$ with an average error of only $2 \%$.

\subsection{CFD simulations for various PCM orientations}

Fig. 6 presents a comparison of the simulations carried out for the various PCM orientations, i.e. (a) vertical; (b) horizontal; and (c) combined horizontal and vertical, PCM. The contours of predicted temperatures and the velocity vectors in the symmetry plane are presented for each simulation. The velocity profiles in the symmetry plane were plotted for three different cabinet heights: (i) near the bottom of the enclosure at $\mathrm{y}=$ $0.01 \mathrm{~m}$; (ii) in the centreline of the cabinet at $\mathrm{y}=0.38 \mathrm{~m}$; and (iii) near the top at $\mathrm{y}=0.74 \mathrm{~m}$. The predicted average and maximum temperatures in the thermal storage refrigerator are indicated for each of the three PCM orientations.

\subsubsection{Vertical PCM}

As can be observed in Fig. 6 orienting the PCM vertically (Fig 6 (a)) resulted in a stratified temperature profile with a cold zone at the bottom and a warm zone at the top. The maximum temperature of $14.8^{\circ} \mathrm{C}$ was predicted for the top right corner and the average temperature in the compartment was $11.2^{\circ} \mathrm{C}$. The velocity vectors indicated a circular airflow pattern, with air flow along the walls and a region of air recirculation in the bottom right corner. The air in the centre of the compartment was effectively stagnant. The velocity profile plot indicated that the air velocity was zero at the PCM surface and then increased rapidly as the distance from the PCM increased reaching a maximum velocity value of $0.23 \mathrm{~m} . \mathrm{s}^{-1}$ at the bottom of the compartment, directly below the PCM surface. The air velocity then decreased and approached zero in the top half of the compartment. The zone with the highest velocity was the hydrodynamic boundary layer and its thickness increased in the flow direction. The velocity profile predicted for the vertical PCM was very similar to that for flow adjacent to a vertical cold plate placed in a warm environment without limiting walls, as described by Çengel [12].

\subsubsection{Horizontal PCM}

The temperature contours with a horizontal PCM (b) showed a slightly more homogeneous temperature distribution than that found with the PCM positioned vertically and the average temperature in the compartment was $2.4^{\circ} \mathrm{C}$ lower. The surface area of the PCM was the same for both orientations simulated; therefore the results were directly comparable. The velocity vectors, which were colour coded by velocity magnitude showed that the cold denser air flowed along the PCM towards the centre and then flowed down to the bottom of the compartment producing recirculation in the bottom corners as the flow was directed upwards along the (warmer) walls of the enclosure. The cold wall at the top of the refrigerator produced higher velocities and generated two vortices that circulated in opposite directions. In the horizontal PCM configuration, the maximum velocity of $0.3 \mathrm{~m} . \mathrm{s}^{-1}$ was obtained at the centre of the compartment at $\mathrm{y}=0.38 \mathrm{~m}$. 


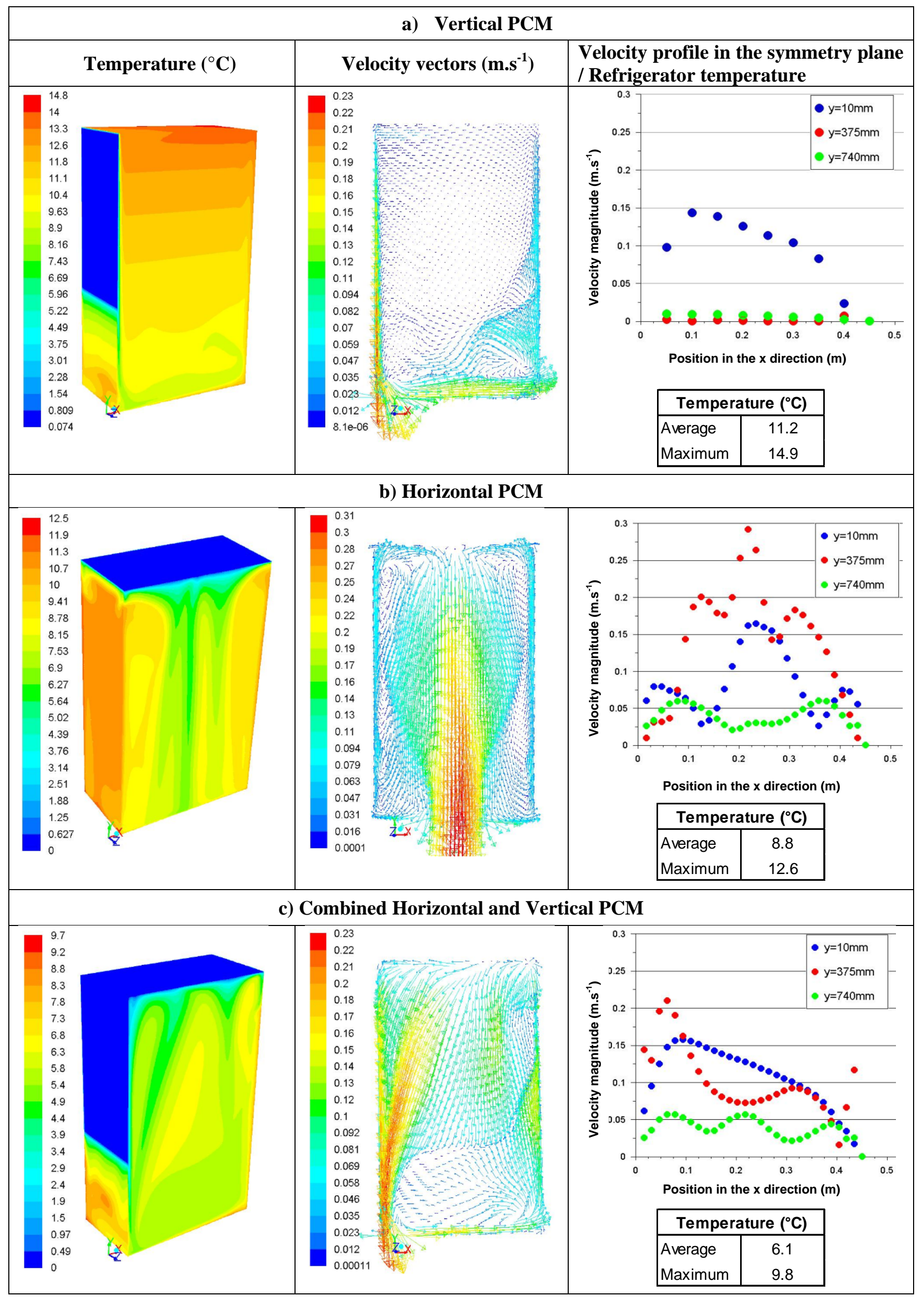

Fig. 6: Simulation comparison between PCM orientations 
The recirculation observed at the top side walls was captured by the velocity profile at $y=0.74 \mathrm{~m}$. At the $\mathrm{x}$ direction positions of $\mathrm{x}=0.075 \mathrm{~m}$ and $\mathrm{x}=0.375 \mathrm{~m}$ the warm air that flowed upwards along the warm walls reached the top of the enclosure where the cold PCM was located. The air was then cooled at the PCM surface becoming denser, and gravity then caused this colder air to sink towards the bottom of the compartment along its vertical centreline. The air then recirculated upwards at the sides of the enclosure, as the warmer air near the bottom was displaced by the sinking cold air at the centre. Overall, the results of the simulations with both the horizontally and vertically oriented PCMs indicated that the air temperature within the natural convection refrigerator significantly exceeded $5^{\circ} \mathrm{C}$, which was the compartment temperature required by the European Standard [19] . One option for reducing the temperature in the refrigerator would be to increase the heat transfer surface area of the PCM, for example, by using a combination of horizontal and vertical PCMs. This scenario was also simulated as described in 4.2.3 below.

\subsubsection{Combined Horizontal and Vertical PCM}

The temperature distribution in the compartment appeared to be very homogeneous with a combined horizontal and vertical PCM (Fig. 2 (c)) and an average air temperature of $6.1^{\circ} \mathrm{C}$ was predicted. The velocity profile indicated that the airflow was a combination of the two previous simulations. The air in the bottom half of the refrigerator had a very similar behaviour to that observed for the vertical PCM simulation, while the top half of the refrigerator provided better air mixing than the vertical PCM alone, as a result of the cold horizontal PCM located in the refrigerator roof. Overall, it appeared that the vertical PCM flow profile had the predominant effect as the maximum velocity was lower than that obtained with the horizontal PCM alone; however, the air mixing in the cavity was significantly enhanced by the horizontal PCM. The velocity profile at $y=0.01 \mathrm{~m}$ was identical to that obtained with a vertical PCM alone (Fig. 2 (a)) and the maximum velocity was predicted for $y=0.38 \mathrm{~m}$, resembling the horizontal PCM simulation (Fig. 2 (b)), however, in this case the maximum velocity position was shifted towards the wall where the vertical PCM was located.

\subsection{Eutectic PCM}

The effect of employing a eutectic PCM on the thermal storage refrigerator temperature was also modelled using the CFD software. Eutectic mixtures are solutions of salts in water that have a phase transition temperature below $0^{\circ} \mathrm{C}$. The proportion of salts in the solution defines the freezing point temperature at which all the constituents crystallise in a eutectic reaction. Water is the ideal PCM, as it is the substance with the highest latent heat content; however, the results for the CFD simulations reported above demonstrated that its phase change temperature was not low enough to maintain the required temperature in the compartment. Therefore, since temperature difference is the main driver for heat transfer, lowering the PCM melting temperature was expected to result in lower refrigerator compartment temperatures. A series of similar simulations to those for the ice PCMs, (the results for which have been reported in 4.2.1 to 4.2.3 above), were carried out using eutectic PCMs at two different melting temperatures i.e. $-2^{\circ} \mathrm{C}$ and $-6^{\circ} \mathrm{C}$.

Table 2 summarizes the average and maximum temperature and velocities for all PCM configurations and PCM melting temperatures.

Table 2: Air temperatures and velocities in refrigerator compartment for all PCM configurations

\begin{tabular}{ccccccc}
\hline \multirow{2}{*}{ PCM orientation } & \multirow{2}{*}{ Melting Point } & \multicolumn{2}{c}{ Temperature $\left({ }^{\circ} \mathbf{C}\right)$} & \multicolumn{2}{c}{ Velocity $\left(\mathbf{m . s}^{-1}\right)$} \\
& & Average & Maximum & Average & Maximum \\
\hline \multirow{2}{*}{ (a) } & \multirow{2}{*}{ Vertical PCM } & Ice at $0^{\circ} \mathrm{C}$ & 11.2 & 14.9 & 0.022 & 0.23 \\
& & Eutectic at $-6^{\circ} \mathrm{C}$ & 7.5 & 12.2 & 0.023 & 0.25 \\
\hline \multirow{2}{*}{ (b) } & \multirow{2}{*}{ Horizontal PCM } & Ice at $0^{\circ} \mathrm{C}$ & 8.8 & 12.6 & 0.049 & 0.34 \\
& & Eutectic at $-6^{\circ} \mathrm{C}$ & 5.0 & 9.8 & 0.054 & 0.36 \\
\hline \multirow{2}{*}{ (c) } & Horizontal and & Ice at $0^{\circ} \mathrm{C}$ & 6.1 & 9.8 & 0.042 & 0.23 \\
& Vertical PCM & Eutectic at $-2^{\circ} \mathrm{C}$ & 4.5 & 8.9 & 0.043 & 0.28 \\
\hline
\end{tabular}

The data presented in Table 2 shows that a lower phase change temperature resulted in higher velocities and lower temperatures in the thermal storage refrigerator. It is also seen that the average velocity was almost doubled with the combined horizontal and vertical PCM (c) as compared with the vertical PCM (a), hence the more homogenous temperature distribution obtained with this configuration. However, using a eutectic with a lower phase change temperature resulted in a reduced thermal energy storage capacity, i.e. lower latent heat value. At $-2^{\circ} \mathrm{C}$, the eutectic stored $8.1 \%$ less cooling energy than water/ice and the eutectic at $6^{\circ} \mathrm{C}$ had $17.4 \%$ less cooling energy capacity. In practice, applying a eutectic PCM achieved lower 
temperatures in the compartment, but the refrigerator energetic autonomy was reduced as compared with an ice PCM.

\subsection{Drawer compartment}

A further CFD simulation was carried out based on the horizontal PCM alone model using ice, but the height of the refrigerator compartment was reduced from $0.75 \mathrm{~m}$ to $0.35 \mathrm{~m}$, to model the temperature and velocity field for a smaller enclosure, a typical application for which would be a drawer refrigerator. The results for this simulation are presented in Fig. 7.
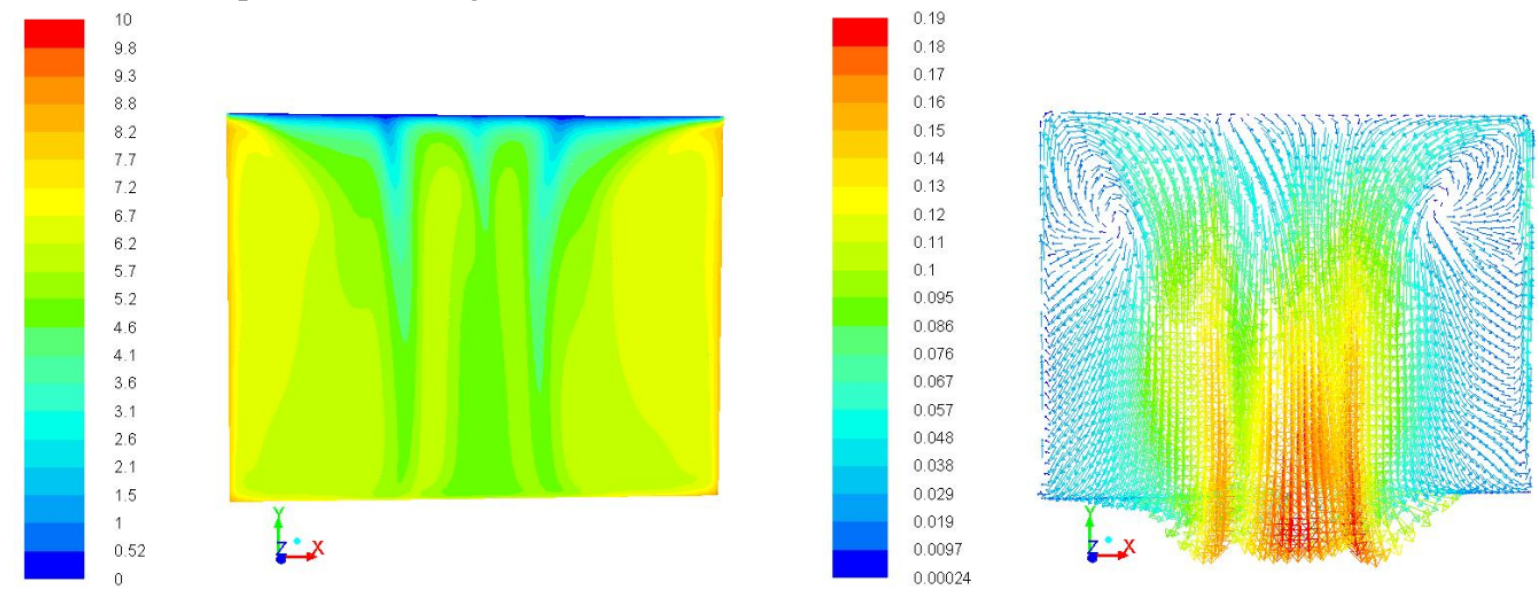

Fig. 7: Steady state temperatures $\left({ }^{\circ} \mathrm{C}\right)$ and velocity vectors $\left(\mathrm{m} \cdot \mathrm{s}^{-1}\right)$ at the symmetry plane $(\mathrm{z}=0.23 \mathrm{~m})$, for a refrigerated drawer compartment with a horizontal PCM

On reducing the enclosure height by nearly half, the average temperature and maximum velocity dropped from $8.8^{\circ} \mathrm{C}$ and $0.34 \mathrm{~m} . \mathrm{s}^{-1}$ for the full height refrigerator compartment with a horizontal $\mathrm{PCM}$, to $6.3^{\circ} \mathrm{C}$ and $0.19 \mathrm{~m} . \mathrm{s}^{-1}$ in the refrigerated drawer compartment incorporating a horizontal PCM.

\section{Conclusions}

CFD simulations were used to identify the best performing (i.e. optimal for energy efficiency and most uniform temperature distribution) design options for a novel, household thermal storage refrigerator. The effect of PCM orientation, phase change temperature and compartment height on refrigerator temperatures were investigated through simulation. The CFD results indicated that a eutectic PCM must be employed to achieve an average compartment temperature of $5^{\circ} \mathrm{C}$. The refrigerator energetic autonomy (length of time that the compressor is off) can be maximised by employing a eutectic with a phase change temperature close to $0^{\circ} \mathrm{C}$. Considering the results for all the simulations, combining horizontal and vertical PCMs in a full height compartment is a viable option. The required performance can also be obtained for the same volume (storage capacity) by dividing the compartment into two drawers and using a horizontal PCM in each drawer, with ice only.

The experimental temperatures obtained from the prototype refrigerator incorporating a horizontal (ice) PCM were in close agreement with the CFD simulations. Additional experiments are required to validate the velocity profile with the horizontal PCM configuration.

The design options described in the paper will be used to develop a commercial thermal storage refrigerator. The new household refrigerator design will also incorporate DDC. Applying these two technologies on a worldwide scale would have a major effect on reducing environmental impact, since the long off-time of the thermal storage refrigerator would reduce electricity demand for a constant supply of energy making the use of renewable energies with intermittent generation capacity easier to integrate into the electricity supply grid.

\section{Acknowledgements}

The financial support of the Engineering and Physical Sciences Research Council (EPSRC) and Adande Refrigeration is gratefully acknowledged. 


\section{REFERENCES}

[1] DEFRA. Act on $\mathrm{CO}_{2}$ Calculator: Data, Methodology and Assumptions Paper. 2008 Available: www.defra.gov.uk/environment/climatechange/uk/individual/actonco2 2008 [Last accessed 16 May 2010].

[2] Negrão C O R, Hermes C J L. Energy and cost optimization of household refrigerators: A simulatedbased design approach. 23rd IIR Congress - Refrigeration for Sustainable Development 2011, Prague, Czech Republic.

[3] Market Transformation Programme. Innovation Briefing Note IBNC16: Vacuum insulated panels for refrigerated appliances. $2006 . \quad$ Available: http://efficientproducts.defra.gov.uk/spm/download/document/id/667 [Last accessed 17 July 2008].

[4] Jähnig D I, Reindl D T, Klein S A. A semi-empirical method for representing household refrigerator/freezer compressor calorimeter test data. ASHRAE Transactions 2000;106.

[5] Bansal P K. Developing new test procedures for household refrigerators: harmonisation issues and future R\&D needs - a review. International Journal of Refrigeration 2003;26:735-48.

[6] Azzouz K, Leducq D, Gobin D. Enhancing the performance of household refrigerators with latent heat storage: An experimental investigation. International Journal of Refrigeration 2009;32:1634-44.

[7] Cheng W-L, Mei B-J, Liu Y-N, Huang Y-H, Yuan, X-D. A novel household refrigerator with shapestabilized PCM (Phase Change Material) heat storage condensers: An experimental investigation. Energy 2011; 36:5797-804.

[8] Gin B, Farid M M, Bansal P K. Effect of door opening and defrost cycle on a freezer with phase change panels. Energy Conversion and Management 2010;51:2698-706.

[9] Laguerre O, Derens E, Palagos B. Study of household refrigerator temperature and analysis of factors affecting temperature: A French survey. International Journal of Refrigeration 2002;25:6539.

[10] James S J, Evans J, James C. A review of the performance of household refrigerators. Journal of Food Engineering 2008;87:2-10.

[11] Amara B S, Laguerre O, Charrier-Mojtabi M C, Lartigue B, Flick D. PIV measurement of the flow field in a household refrigerator model: Comparison with 3D simulations. International Journal of Refrigeration 2008;31:1328-40.

[12] Çengel Y A. Natural Convection. Heat Transfer: A Pratical Approach. McGraw-Hill; 2003.

[13] Laguerre O, Amara B S, Flick D. Experimental study of heat transfer by natural convection in a closed cavity: application in a household refrigerator. Journal of Food Engineering 2005;70:523-37.

[14] Market Transformation Programme. BNXS41: Dynamic demand control of household appliances. 2008. Available: http://efficient-products.defra.gov.uk/spm/download/document/id/658 [Last accessed 5 January 2012].

[15] Laguerre O, Flick D. Heat transfer by natural convection in household refrigerators. Journal of Food Engineering 2004;62:79-88.

[16] Colomer G, Costa M, Cònsul R, Oliva, A. Three-dimensional numerical simulation of convection and radiation in a differentially heated cavity using the discrete ordinates method. International Journal of Heat and Mass Transfer 2004;47:257-69.

[17] ANSYS. Using the solver. ANSYS FLUENT 12.0 User's Guide. ANSYS Inc. 2009.

[18] Amara B S, Laguerre O, Charrier-Mojtabi M-C, Lartigue B, Flick D. Numerical and Experimental study of convective airflow in a household refrigerator model. Eurotherm Seminar 77 - Heat and Mass transfer in Food processing, 2005, Parma, Italy.

[19] EN 153:2006 Methods of measuring the energy consumption of electric mains operated household refrigerators, frozen food storage cabinets, food freezers and their combinations, together with associated characteristics. European Committee for Standardization. 2006. 